\title{
The Structural Properties of Fe-Ti-B Based Alloys Produced by Mechanical Alloying
}

\author{
O. KON*, U. SEN \\ ${ }^{a}$ Sakarya University, Technical Education Faculty, Metal Education \\ Department, 54187, Serdivan Sakarya, Turkey \\ ${ }^{b}$ Sakarya University, Engineering Faculty, Department of Metallurgy and \\ Materials Engineering, 54187, Serdivan Sakarya, Turkey
}

\begin{abstract}
In the present study, the production of Fe-Ti-B based alloys was realized and their structure and properties were investigated. Mechanical alloying proceeds by the continual cold welding and fracturing of the constituent mixture of $\mathrm{Ti}+4 \mathrm{~B}+5 \mathrm{Fe}$ powder when subjected to the large compressive forces of a high speed mill. The powder charge together with $7 \mathrm{~mm}$ diameter steel balls were loaded into a tool steel grinding container at approximately $350 \mathrm{RPM}$ for $20 \mathrm{~h}$. The samples were shaped as cylinder of $\varnothing 15 \times 8 \mathrm{~mm}$ dimensions by uniaxial pressing at $450 \mathrm{MPa}$. Then, the green body materials were produced by sintering at $1100{ }^{\circ} \mathrm{C}$ for $1-4 \mathrm{~h}$ in argon atmosphere. The morphology of composite materials was investigated by optical microscopy and scanning electron microscopy and phase analysis was realized by x-ray diffraction analysis. The bulk densities of the materials were measured using by Archimedes method. Also, the micro-hardness of the samples was measured by Vickers indentation technique. As a result, $\mathrm{Fe}$, iron boride $\left(\mathrm{FeB}, \mathrm{Fe}_{2} \mathrm{~B}\right)$ and titanium boride $\left(\mathrm{TiB}_{2}\right)$ phases were detected in the phase analysis of the Fe-Ti-B based materials. The hardness of the materials was measured between $1107 \mathrm{HV}_{0.05}$ and $1551 \mathrm{HV}_{0.05}$, depending on sintering time. The densities of the samples were determined between $4.205 \mathrm{~g} / \mathrm{cm}^{3}$ and $4.219 \mathrm{~g} / \mathrm{cm}^{3}$.
\end{abstract}

DOI: 10.12693 /APhysPolA.127.1214

PACS: 81.20.Ev, 06.30.Dr, 62.20.Qp

\section{Introduction}

The exothermic dispersion process technology was used with mechanical alloying and sintering process to produce a new modified composite having $\mathrm{TiB}_{2}$ and $\mathrm{Fe}_{2} \mathrm{~B}$ reinforcement particulates. This process utilizes a mixture of powders of the ferrous alloy powders components with a third metallic component. Heating of this mixture causes the exothermal interaction between the components. Steel-based material is a kind of metal material of extensive application, and has such merit as low price, no pollution in the fabrication, convenience in the reuse, and good process ability. Moreover, its mechanical and physical properties can be adjusted by heat treatment. $\mathrm{TiB}_{2}$ particles are selected because they possess a very high hardness, high melting point, high strength, excellent corrosive resistance, good thermodynamic stability as well as good thermal conductivity [1].

Recently, MA has often been used to synthesize the metal carbides, borides and silicides, which provide a novel route to prepare fine-grained ceramic powders. MA is an alternative solid state technique by which novel materials may be synthesized from elemental or pre-alloyed powders $[2-4]$.

It is well established that the incorporation of hard ceramic particulates (e.g. carbides and borides) to ferrous matrices can significantly improve certain material properties, such as wear resistance, toughness and

*corresponding author; e-mail: okon42@hotmail.com strength. Therefore, ceramic particulate reinforced Fe and steel matrix composites have received considerable attention in recent years. Titanium diboride $\left(\mathrm{TiB}_{2}\right)$, possessing outstanding features such as high melting point $\left(2790^{\circ} \mathrm{C}\right)$, high hardness $(33 \mathrm{GPa})$, high modulus $(530 \mathrm{GPa})$ and low density $\left(4.451 \mathrm{~g} / \mathrm{cm}^{3}\right)$, is another potential reinforcement. Generally, there are several methods of fabricating the particulate reinforced steel matrix composites, such as powder metallurgy (PM), conventional melting and casting, carbo-thermic reduction, self-propagating high-temperature synthesis (SHS) (also called combustion synthesis) and alumino-thermic reduction $[5,6]$.

A ternary system, which gains the attention of scientists, is the Fe-Ti-B system because of the formation of $\mathrm{TiB}_{2}$ particles. These particles have ideal properties for being used as a reinforcing material, such as high hardness and melting point, good corrosion resistance and thermal conductivity. The majority of studies focus on the $\mathrm{Fe}-\mathrm{TiB}_{2}-\mathrm{TiFe}_{2}$ region of the ternary diagram, while the $\mathrm{Fe}-\mathrm{TiB}_{2}-\mathrm{Fe}_{2} \mathrm{~B}$ region remains unexplored, although it presents a great potential [7].

In present study, fabrication, structural and mechanical properties of the in-situ $\mathrm{TiB}_{2}$ and $\mathrm{Fe}_{2} \mathrm{~B}$ reinforced steel matrix composites by the mechanical alloying treatment of the powders and sintering process was studied.

\section{Experimental procedure}

Ferrous boron, ferrous niobium and Armco-iron (ASC.100.29) powders were used in the study. The nominal compositions (wt.\%) of ferrous boron and ferrous titanium alloys used in the study were as follows: $19.63 \%$ 
$\mathrm{B}, 0.44 \% \mathrm{C}, 0.05 \% \mathrm{Al}, 0.98 \% \mathrm{Si}$, balance $\mathrm{Fe}$ and $68.4 \% \mathrm{Ti}$, $0.13 \% \mathrm{C}$, balance Fe, respectively. Ferrous boron and titanium were grounded by ring grinder and resieved to be $100 \mu \mathrm{m}$ grain sizes. At the first step of the study, the mixture of $\mathrm{Ti}+4 \mathrm{~B}+5 \mathrm{Fe}$ powders was mechanically alloyed in the attritor at $350 \mathrm{rpm}$ for $20 \mathrm{~h}$ in argon atmosphere. The steel balls with $7 \mathrm{~mm}$ diameter were used as a grinding media with a ball-to-powder ratio of 5:1. At the second step, mechanically alloyed powders were shaped as cylindrical coupons at the dimensions of $15 \mathrm{~mm}$ in diameter and $8 \mathrm{~mm}$ in thickness by uniaxial dry pressing under the pressure of $450 \mathrm{MPa}$. Polyvinyl alcohol was used as a binder material. After shaping, samples were dried at $80^{\circ} \mathrm{C}$ for $24 \mathrm{~h}$ in an oven. Dried samples were sintered in an electrical furnace with a heating rate of $6{ }^{\circ} \mathrm{C} / \mathrm{min}$ at $1100{ }^{\circ} \mathrm{C}$ for $1-4 \mathrm{~h}$ in the Ar atmosphere. Then, the samples were cooled down to room temperature in the furnace.

The microstructure of sintered materials was observed by using optical microscope (Nickon Epiphot) and scanning electron microscope (SEM) (Jeol JSM $6060 \mathrm{LV}$ ) to the samples which were ground on silicon carbide papers to 1200 grit, and then progressively polished with, $0.3 \mu \mathrm{m} \mathrm{Al} \mathrm{O}_{3} \mathrm{O}_{3}$ paste. An x-ray diffractometer (Rigaku $\mathrm{XRD} / \mathrm{D} / \mathrm{MAX} / 2200 / \mathrm{PC}$ ) with $\mathrm{CuK}_{\alpha}$ radiation was used to analyze the constituent phases in the microstructure. The bulk densities of the materials were measured by Archimedes method. Also, the micro-hardness of the samples was measured by using Future Tech FM 700 microhardness tester by Vickers indentation technique with $50 \mathrm{~g}$ load.

\section{Results and discussions}

Figure 1 shows the SEM image and EDS analysis of the mechanically alloyed $\mathrm{Ti}+4 \mathrm{~B}+5 \mathrm{Fe}$ powders. As shown on Fig. 1a, the powder was established well ground and agglomerated structure, and EDS analysis (Fig. 1b) shows that the elemental distribution of the powder which was including $\mathrm{Fe}, \mathrm{Ti}$ and $\mathrm{B}$ beside trace element of $\mathrm{Al}$ which was coming from the ferrous alloys. Figure $2 a$ and $b$ shows optical and SEM images of the mechanically alloyed and sintered $\mathrm{Ti}+4 \mathrm{~B}+5 \mathrm{Fe}$ alloys at $1100^{\circ} \mathrm{C}$ for $4 \mathrm{~h}$. Optical and SEM micrographs include well distributed different color grain structure phases. X-ray diffraction analysis showed that the phases formed in the sintered sample at $1100^{\circ} \mathrm{C}$ for $1 \mathrm{~h}$ are $\mathrm{Fe}_{2} \mathrm{~B}, \mathrm{FeB}, \mathrm{TiB}_{2}$ and Fe. It is clear from the $\mathrm{X}$-ray diffraction analysis that the alloy produced from the mechanically alloyed powders includes different boride phases and Fe and so, microstructure of the produced samples includes these phases' grains as different contrast. EDS analysis supported the X-ray diffraction analysis as shown in Fig. 2c, d and e. Possible reactions took place during the sintering process are follows [8-10].

$$
\begin{aligned}
& \mathrm{Ti}+2 \mathrm{FeB} \rightarrow \mathrm{TiB}_{2}+2 \mathrm{Fe}, \\
& \mathrm{Fe}+\mathrm{FeB} \rightarrow \mathrm{Fe}_{2} \mathrm{~B} .
\end{aligned}
$$
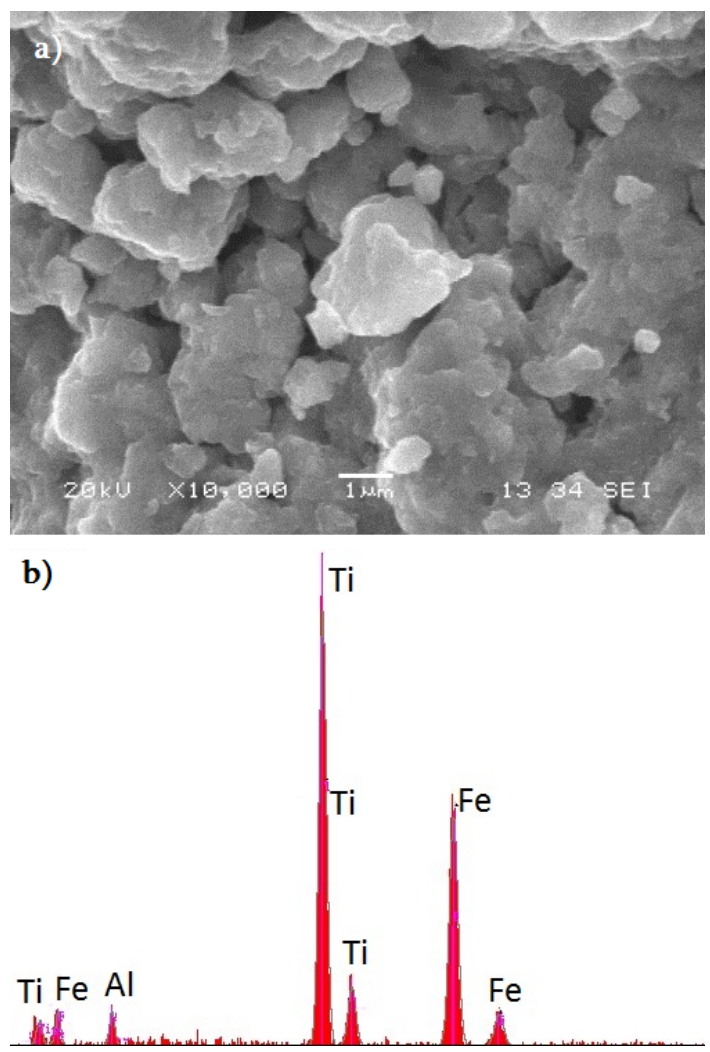

Fig. 1. SEM images and EDS analysis of mechanically alloyed $\mathrm{Ti}+4 \mathrm{~B}+5 \mathrm{Fe}$ powders.

Ferrous boron includes $\mathrm{FeB}$ phase and ferrous titanium includes $68.4 \% \mathrm{Ti}$ by wt. As a result, $\mathrm{TiB}_{2}$ and $\mathrm{Fe}_{2} \mathrm{~B}$ phases realized from the ferrous alloys. Raghavan's phase diagrams of Fe-Ti-B demonstrate that the phases took place in the diagram of $\mathrm{Ti}+4 \mathrm{~B}+5 \mathrm{Fe}$ concentration are $\mathrm{Fe}_{2} \mathrm{~B}, \mathrm{TiB}_{2}$ and Fe. As shown from Fig. 3 that the presence phases in the study includes $\mathrm{FeB}$ phase. It is probable that the reactions to be realized in the powder mixture will be continue during sintering process at $1100{ }^{\circ} \mathrm{C}$ over $1 \mathrm{~h}$ sintering time up to used up the $\mathrm{FeB}$ phase in.

Figure 4 shows the density and micro-hardness of the samples sintered at $1100{ }^{\circ} \mathrm{C}$ for $1-4 \mathrm{~h}$. As shown from the figure that the increase in the sintering time caused to increase of densities of the sintered samples. As known, the density of the sintered materials increased with increase in sintering time [11]. It is possible that the increase in sintering time caused to decrease of porosity and realized the reactions took place in the powder mixture.

Vickers micro-hardness test was realized on the sintered samples. As shown from Fig. 4, increase in sintering time caused to increase the formation of boride phases and decrease of the porosity in the sintered samples. The samples produced include $\mathrm{Fe}$ and borides of $\mathrm{Ti}$ and Fe. So it's an in-situ composite structure. The hard boride phases increment will be caused to increase of the materials hardness [12]. The hardness of the $\mathrm{Fe}_{2} \mathrm{~B}$ and $\mathrm{TiB}_{2}$ phases is between $1500-1700 \mathrm{HV}$ [13] and $2900 \mathrm{HV}$ 

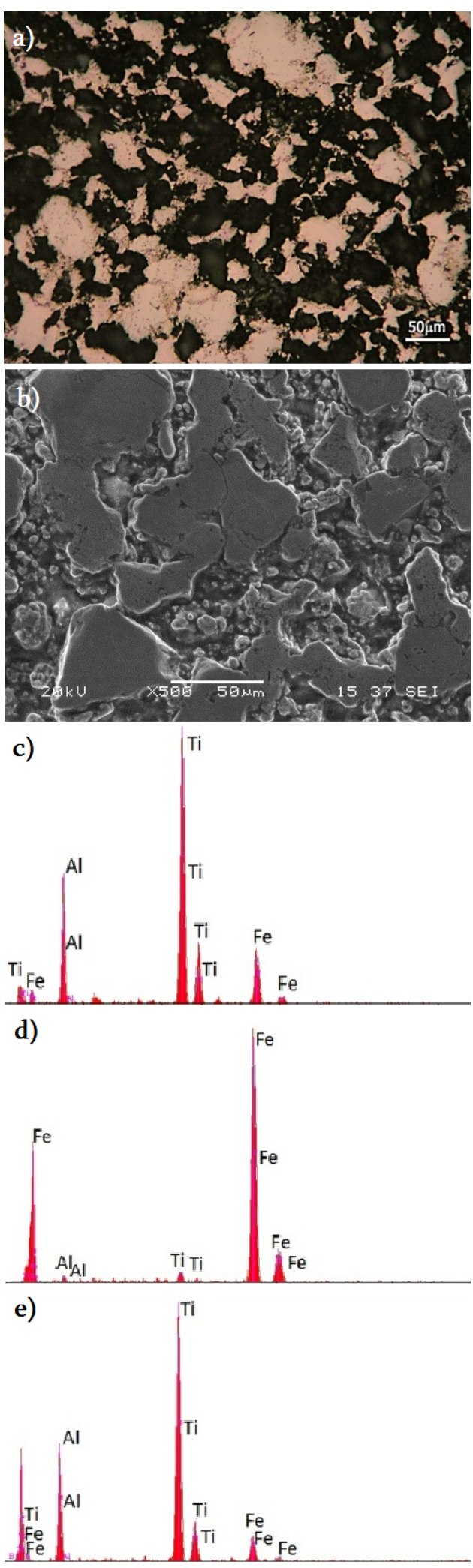

Fig. 2. a) Optical and (b) SEM micrographs of $\mathrm{Ti}+4 \mathrm{~B}+5 \mathrm{Fe}$ alloys at $1100{ }^{\circ} \mathrm{C}$ for $4 \mathrm{~h}$ and (c, d and e) EDS analysis of marked on SEM image as 1,2 and 3, respectively.

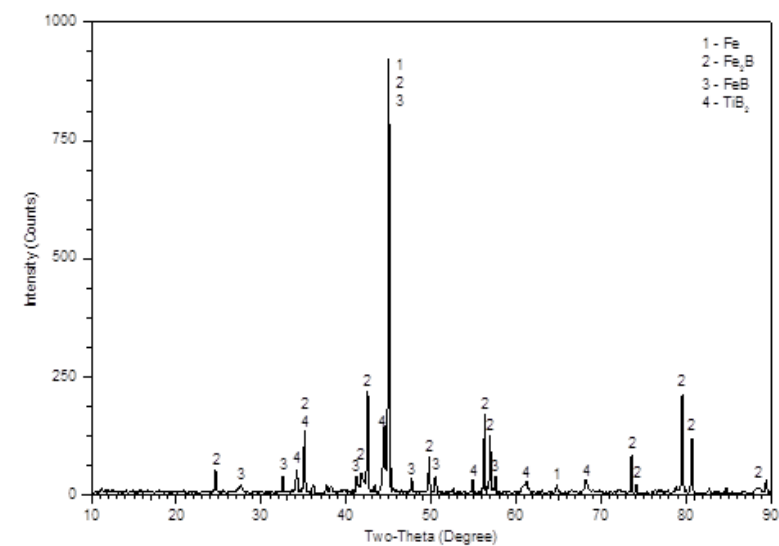

Fig. 3. X-ray diffraction analysis of $\mathrm{Ti}+4 \mathrm{~B}+5 \mathrm{Fe}$ alloys at $1100{ }^{\circ} \mathrm{C}$ for $1 \mathrm{~h}$.

to $3400 \mathrm{HV}$ [14].

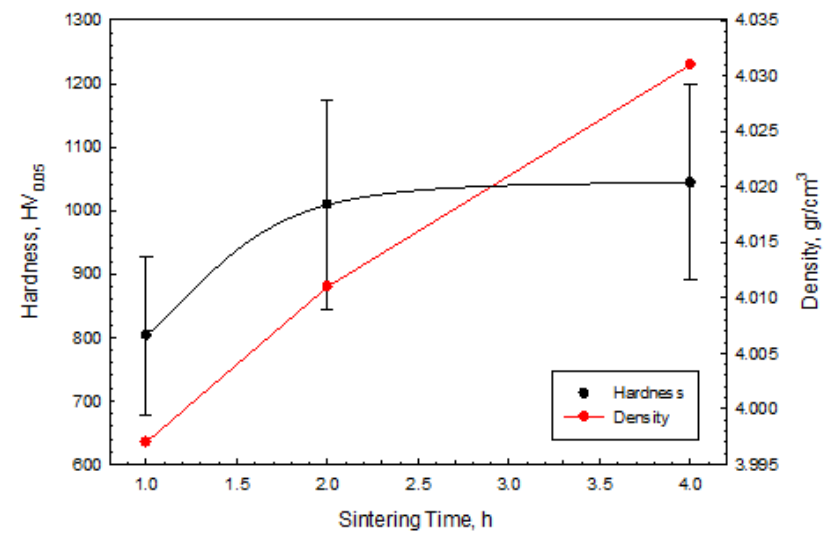

Fig. 4. Density and hardness of the $\mathrm{T} i+4 \mathrm{~B}+5 \mathrm{Fe}$ alloys sintered at $1100{ }^{\circ} \mathrm{C}$.

\section{Conclusions}

Based on all of the experimental results obtained in this work, the following conclusions could be drawn:

Mechanically alloyed $\mathrm{Ti}+4 \mathrm{~B}+5 \mathrm{Fe}$ powders produced from the commercial ferrous alloys were established well ground and agglomerated structure.

The powders sintered at $1100{ }^{\circ} \mathrm{C}$ can produce in-situ composites with both $\mathrm{TiB}_{2}$ and $\mathrm{Fe}_{2} \mathrm{~B}$ as reinforcing particles. Stable phases present in the ternary Fe-Ti-B diagram are formed.

The presence phases in the sintered samples include $\mathrm{Fe}_{2} \mathrm{~B}, \mathrm{TiB}_{2}, \mathrm{Fe}$ and $\mathrm{FeB}$ phases.

Increase in the sintering time caused to increase of density of the sintered samples. Increase in sintering time caused to increase the formation of boride phases and decrease of the porosity in the sintered samples.

Increase in the sintering time caused to increase of the hardness of the sintered in-situ composites of $\mathrm{TiB}_{2}, \mathrm{Fe}_{2} \mathrm{~B}$ and Fe. Increase in sintering time caused to increase the 
formation of boride phases and decrease of the porosity in the sintered samples, an so the hardness of the in-situ composite increased.

\section{Acknowledgments}

This paper was supported by T.C. Sakarya University BAPK project, numbered as: 2010-01-08-010

\section{References}

[1] Z. Xue, J. Kuang, H. Fu, Mat.-wiss. u. Werkstofftech 39, 557 (2008).

[2] W. Tang, Z. Zheng, Y. Wu, J. Wang, J. Lü, J. Liu, Trans. Nonferrous Met. Soc. China 16, 613 (2006).

[3] T.S. Ward, W. Chen, M. Schoenitz, R.N. Dave, E.L. Dreizin, Acta Materialia 53, 2909 (2005).

[4] J.J. Sunol, A. Gonzalez, J. Saurina, L. Escoda, P. Bruna, Materials Sci. and Engineering A 375, 874 (2004).

[5] Y. Wang, Z.Q. Zhang, H.Y. Wang, B.X. Ma, C.Q. Jiang, Materials Sci. and Engineering: A 422, 339 (2006).

[6] Y. Wang, H.Y. Wang, K. Xiu, H.Y. Wang, Q.C. Jiang, Materials Letters 60, 1533 (2006).
[7] M. Darabara, G.D. Papadimitriou, L. Bourithis, Surface $\&$ Coatings Technology 201, 3518 (2006).

[8] J. Balogh, L. Bujdoso, T. Kemeny, I. Vincze, Journal of Physics: Condensed Matter 9, 503 (1997).

[9] I. Campos-Silva, M. Ortiz-Dominguez, C. TapiaQuintero, G. Rodrguez-Castro, M.Y. Jimenez-Reyes, E. Chavez-Gutierrez, Journal of Materials Engineering and Performance 21, 1714 (2012).

[10] D. Demirskyi, Y. Sakka, Journal of the European Ceramic Society 35, 405 (2015).

[11] S.J.L. Kang, in: Sintering: Densification, Grain Growth and Microstructure, Oxford: Elsevier Butterworth Heinemann, 2005.

[12] Y. Li, M.L. Swartz, R.W. Phillips, B.K. Moore, T.A. Roberts, Journal of Dental Research 64, 1396 (1985).

[13] S.O. Yilmaz, M. Ozenbas, Journal of Mater Science 44, 3273 (2009).

[14] G. Hilz, H. Holleck, Materials Science and Engineering A 139, 268 (1991). 